\title{
Corrigendum
}

\section{Das Gesetz vom iterierten Logarithmus mit Anwendungen auf die Zahlentheorie}

Math. Annalen 180, 75-94 (1969)

\section{WaLter Philipp}

Herr Prof. S. K. Zaremba machte mich freundlicherweise auf eine Reihe von Ungenauigkeiten und irreführenden Bemerkungen aufmerksam, die ich nachstehend auszubügeln versuche.

1) Auf S. 80 habe ich behauptet: Satz 2 folgt nun sofort aus Satz 1. Das ist leicht übertrieben. Man muß dazu die Behauptung in Satz 1 durch folgende stärkere ersetzen, die in der Arbeit auch tatsächlich bewiesen wurde, nämlich durch:

Dann ist

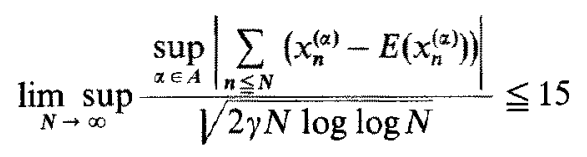

ein fast sicheres Ereignis.

2) Die an Satz 1 anschließende Bemerkung muß nun gestrichen werden, obwohl man ohne große Schwierigkeit sehen kann, daß sie im wesentlichen auch für den neuen Sachverhalt gültig bleibt. Ich bin gerne bereit, die neue Version dem interessierten Leser zu senden.

3) Formel (8) soll lauten

$$
\limsup _{N \rightarrow \alpha} \frac{R(N, \alpha, \beta)}{\sqrt{N \log \log N}}=\sqrt{2(\beta-\alpha)(1-\beta+\alpha)}
$$

4) In Formel (9) und in der 7. Zeile von unten auf S. 78 ist die Konstante 1 durch $\frac{1}{\sqrt{2}}$ zu ersetzen. 